\title{
Distribusi Spasial Kualitas Perairan di Perairan Kawasan Taman Nasional Karimunjawa
}

\author{
Nabilah Rizki ${ }^{* *}$, Lilik Maslukah ${ }^{1}$, Denny Nugroho Sugianto ${ }^{1}$, Muhammad Zainuri $^{1}$, \\ Aris Ismanto ${ }^{1}$ dan Anindya Wirasatriya ${ }^{1}$
}

${ }^{1}$ Departemen Oseanografi, Jurusan Ilmu Kelautan Fakultas Perikanan dan Ilmu Kelautan Jl. Prof. H. Sudarto, SH Tembalang, Telp/fax (024) 7474698 Semarang 50275

*Email: nabilahrizki@gmail.com

\begin{abstract}
Abstrak
Kepulauan Karimunjawa merupakan salah satu kawasan konservasi di Indonesia yang kaya akan sumberdaya ekosistemnya. Secara sosial-ekonomi masyarakat sangat bergantung pada sumber daya pesisir, sehingga dapat berdampak pada kondisi perairan. Tujuan penelitian yaitu untuk mengetahui kondisi kualitas perairan di perairan Kawasan Taman Nasional Karimunjawa yang berkaitan dengan kehidupan ekosistem. Analisisa kualitas perairan dilakukan dengan membandingkan hasil konsentrasi secara spasial dengan baku mutu kualitas perairan Kep. Men. LHK RI No. 5 Tahun 2004. didapatkan bahwa kualitas perairan meliputi konsentrasi suhu sekitar 29-30 ${ }^{\circ} \mathrm{C}$, salinitas 32 - 35 ppm, DO 9 - $11 \mathrm{mg} / \mathrm{L}, \mathrm{pH}$ 7,6 - 7,95 dan kecerahan 1- 7 meter yang berdasarkan baku mutu perairan laut untuk kehidupan biota dari KEP. MEN. KLH RI No. 5 tahun 2004, perairan Kawasan Taman Nasional Karimunjawa sangat baik yang belum melebihi batas baku mutu.
\end{abstract}

Kata kunci : Kualitas perairan, Perairan Karimunjawa, baku mutu dan distribusi spasial

\begin{abstract}
Karimunjawa Islands is one of the conservation areas in Indonesia which is rich in ecosystems. The socioeconomy of the community is very dependent on coastal resources, so that it has an impact on water conditions. The research objective is to see the condition of the waters in the waters of the Karimunjawa National Park which are related to the living ecosystem. Analysis of water quality is carried out by monitoring the results of spatial concentration with waters quality standards of Kep. Men. LHK RI No. 5 of 2004. found that water quality includes a temperature concentration of around $29-30^{\circ} \mathrm{C}$, salinity 32 - $35 \mathrm{ppm}, \mathrm{DO} 9-11 \mathrm{mg} / \mathrm{L}$, pH 7.6 7.95 and an area of 1-7 meters based on quality standards marine waters for biota from KEP. MEN. KLH RI No. 5 of 2004, Karimunjawa National Park waters area is very good which has not exceeded the quality standard.
\end{abstract}

\section{Keywords : Water quality, Karimunjawa water, quality standards and spatial distribution}

\section{PENDAHULUAN}

Kepulauan Karimunjawa merupakan salah satu kawasan perlindungan nasional di Indonesia yang dikelola oleh Balai Taman Nasional Karimunjawa sejak tahun 1988. Kawasan konservasi ini terbagi atas konservasi zona darat, pesisir dan laut. Ekosistem pada zona pesisir didominasi oleh ekosistem mangrove. Namun, berdasarkan penelitian Suryanti (2010), mengatakan bahwa telah terjadi degradasi ekosistem mangrove di Kawasan Taman Nasional Karimunjawa sebesar 20,69 ha, salah satunya akibat adanya konversi lahan mangrove menjadi kawasan tambak udang vaname.

Dominansi aktivitas pesisir dilakukan oleh masyarakat di Kawasan Taman Nasional Karmunjawa adalah budidaya tambak udang vanamme. Aktivitas tersebut sangat berkaitan dengan kondisi kualitas perairan pesisir dari pembuangan limbah budidaya tambak. Menurut kajian yang telah dilakukan oleh Yusidarta et al., (2018), aktivitas masyarakat didominansi oleh aktivitas budidaya tambak udang vaname di Kawasan Taman Nasional Karimunjawa dengan kondisi pengelolaan limbah yang dibuang secara langsung ke badan perairan tanpa adanya proses filterasi air limbah, karena tidak tersedianya Instalasi Pengelolaan Air Limbah (IPAL). Sehingga, hal ini dapat menimbulkan dugaan bahwa perairan Kawasan Taman Nasional Karimunjawa dapat mengalami perubahan konsentrasi kualitas perairan dalam kurung waktu tertentu.

Ditinjau dari aktivitas masnyarakat yang sangat tidak terlepas dari kekayaan sumber daya pesisir, maka kualitas perairan di perairan Kawasan Taman Nasional Karimunjawa dalam aspek kehidupan ekosistem perairan perlu dikelola dengan baik. Untuk itu diperlukan data dan informasi mengenai kondisi kualitas perairan secara 
berkala sebagai bahan masukkan dalam rencana pengelolaan lingkungan baik jangka pendek maupun jangka panjang.

\section{MATERI DAN METODE}

\section{Materi Penelitian}

Materi penelitian dalam penelitian ini meliputi data primer yang diambil dilapangan dan data sekunder sebagai pendukung penelitian. Data primer merupakan hasil pengukuran lapangan yang berupa data kualitas perairan, meliputi parameter suhu, salinitas, DO (Dissolved Oxygen), $\mathrm{pH}$ dan kecerahan. Sedangkan data sekunder merupakan data pendukung yang merupakan data pasang surut yang diunduh dari IPASOET BIG dan baku mutu perairan untuk kehidupan biota berdasarkan publikasi KEP. MEN. LHK RI No. 51 tahun 2004.

\section{Metode Penelitian}

Penelitian ini dilakukan pada 4 September 2019 yang berlokasi di perairan Kawasan Taman Nasional Karimunjawa, Kabupaten Jepara, Jawa tengah. Metode yang digunakan dalam penelitian ini adalah metode kuantitatif yang menurut Sugiyono (2009), adalah teknik mengolah data angka yang secara terukur untuk menghasilkan nilai-nilai berdasarkan kaidah - kaidah ilmiah. Lokasi titik pengukuran kualitas perairan sebanyak 10 titik stasiun yang dijelaskan dalam peta Lokasi pada Tabel 1.

Tabel 1. Koordinat Stasiun Pengukuran Kualitas Perairan

\begin{tabular}{ccc}
\hline \multirow{2}{*}{ Nama Stasiun } & \multicolumn{2}{c}{ Koordinat Stasiun } \\
\cline { 2 - 3 } & Lintang & Bujur \\
\hline Stasiun 1 & $5^{\circ} 49^{\prime} 47.32^{\prime \prime S}$ & $110^{\circ} 25^{\prime} 50.60^{\prime \prime} \mathrm{E}$ \\
Stasiun 2 & $5^{\circ} 49^{\prime} 54.03 " \mathrm{~S}$ & $110^{\circ} 26^{\prime} 18.01^{\prime \prime} \mathrm{E}$ \\
Stasiun 3 & $5^{\circ} 49^{\prime} 37.14^{\prime \prime} \mathrm{S}$ & $110^{\circ} 26^{\prime} 56.30^{\prime \prime} \mathrm{E}$ \\
Stasiun 4 & $5^{\circ} 49^{\prime} 26.23 " \mathrm{~S}$ & $110^{\circ} 27^{\prime} 13.46^{\prime \prime} \mathrm{E}$ \\
Stasiun 5 & $5^{\circ} 48^{\prime} 51.84 " \mathrm{~S}$ & $110^{\circ} 27^{\prime} 34.08^{\prime \prime} \mathrm{E}$ \\
Stasiun 6 & $5^{\circ} 49^{\prime} 0.31 " \mathrm{~S}$ & $110^{\circ} 26^{\prime} 52.44^{\prime \prime} \mathrm{E}$ \\
Stasiun 7 & $5^{\circ} 48^{\prime} 27.81 " \mathrm{~S}$ & $110^{\circ} 26^{\prime} 48.97^{\prime \prime} \mathrm{E}$ \\
Stasiun 8 & $5^{\circ} 48^{\prime} 21.09 " \mathrm{~S}$ & $110^{\circ} 27^{\prime} 2.01^{\prime \prime} \mathrm{E}$ \\
Stasiun 9 & $5^{\circ} 48^{\prime} 5.44 " \mathrm{~S}$ & $110^{\circ} 27^{\prime} 11.41^{\prime \prime} \mathrm{E}$ \\
Stasiun 10 & $5^{\circ} 49^{\prime} 16.19 " \mathrm{~S}$ & $110^{\circ} 25^{\prime} 20.14^{\prime \prime} \mathrm{E}$ \\
\hline
\end{tabular}

\section{Metode Pengukuran Lapangan}

Penentuan lokasi pengukuran lapangan menggunakan metode purposive sampling. Metode ini merepresentasikan keadaan seluruh stasiun yang ditetapkan berdasarkan peneliti (Sugiyono, 2012). Pada penelitian ini menggunakan 10 titik yang diasumsikan mewakili daerah penelitian. Metode di lapangan yang digunakan adalah metode survei untuk memperoleh data kualitas perairan. Pengukuran kualitas dilakukan secara in-situ menggunakan Water Quality Checker AZ 8603. Berdasarkan metode SNI 06-2413-1991 yaitu metode pengujian kualitas fisika air, data kualitas perairan tersebut dilakukan secara in-situ dengan 3 kali pengulangan pada setiap parameter kualitas perairan dan diambil nilai rata - rata. Hal ini untuk mengurangi terjadinya kesalahan pengukuran pada saat pengambilan data di lapangan.

Pengukuran dengan Water Quality Checker AZ Instrument 8603 dilakukan dengan memasukkan sensor ke dalam perairan. Pengukuran salinitas dilakukan dengan refraktometer, dengan mengambil sampel air secara langsung kemudian sampel diletakkan di refraktometer dan diamati nilai salinitas sampel tersebut secara langsung di lapangan. Parameter BOD dilakukan pengukuran dengan metode fisik, yaitu dengan bantuan Instrumen Water Quality Checker AZ Instrument 8603.

\section{Metode Pengolahan Data}

Data kualitas perairan yang telah diambil berupa data $\mathrm{pH}, \mathrm{DO}, \mathrm{BOD}$, suhu, salinitas dan kecerahan yang dilakukan secara in-situ, kemudian dikelompokan dalam bentuk tabel menggunakan Ms. Excel 2010. Selanjutnya dianalisa sesuai pengukuran kondisi lapangan terhadap baku mutu yang telah ditetapkan berdasarkan Kep. Men. KLH RI No. 51 Tahun 2004. 
HASIL

Tabel 2. Konsentrasi Kualitas Perairan Hasil Pengukuran

\begin{tabular}{lccccc}
\hline \multirow{2}{*}{$\begin{array}{c}\text { Titik } \\
\text { Sampel }\end{array}$} & \multicolumn{5}{c}{ Konsentrasi } \\
\cline { 2 - 6 } & DO (mg/l) & pH (mg/l) & $\begin{array}{c}\text { Suhu } \\
\left({ }^{\circ} \mathrm{C}\right)\end{array}$ & Salinitas (\%o) & Kecerahan (m) \\
\hline Stasiun 1 & 7,12 & 7,83 & 27,4 & 34 & 2,4 \\
Stasiun 2 & 7,2 & 7,72 & 22,5 & 33 & 3,6 \\
Stasiun 3 & 8,32 & 7,81 & 27,7 & 32 & 3,75 \\
Stasiun 4 & 6,38 & 7,7 & 28,1 & 33 & 3,8 \\
Stasiun 5 & 7,78 & 7,64 & 28,23 & 34 & 7,7 \\
Stasiun 6 & 8,1 & 7,75 & 28,3 & 33 & 3 \\
Stasiun 7 & 8,26 & 7,92 & 28.65 & 32 & 1,4 \\
Stasiun 8 & 8,17 & 7,81 & 29.3 & 34 & 1,7 \\
Stasiun 9 & 8,34 & 7,89 & 30 & 33 & 2,6 \\
Stasiun 10 & 6,1 & 7,63 & 29 & 35 & 3,4 \\
\hline
\end{tabular}

Parameter kualitas perairan pada 10 stasiun yang telah diukur di lapangan ditampilkan pada Tabel 10. Kualitas perairan yang diukur meliputi parameter DO, $\mathrm{pH}$, suhu, salinitas dan kecerahan. Nilai parameter setiap stasiun memiliki nilai yang berbeda. Parameter DO memiliki konsentrasi tertinggi pada stasiun 9 dengan besar $8,34 \mathrm{mg} / 1$ dan terendah pada stasiun 4 dengan konsentrasi $6,38 \mathrm{mg} / \mathrm{l}$, dengan rata - rata nilai $7,58 \mathrm{mg} / 1$. Konsentrasi BOD memiliki konsentrasi tertinggi pada stasiun 3 dengan besar 0,608 $\mathrm{mg} / \mathrm{l}$ dan terendah pada stasiun 6 yaitu $0,184 \mathrm{mg} / \mathrm{l}$, dengan rata - rata konsentrasi $0,446 \mathrm{mg} / 1$. Pada konsentrasi salinitas tertinggi terletak pada stasiun 5 dan stasiun 7 yaitu $35 \%$ dan terendah pada stasiun 10 dengan nilai konsentrasi $25 \%$, dengan rata - rata konsentrasi $32 \%$. Konsentrasi suhu yang tertinggi mencapai $30^{\circ} \mathrm{C}$ pada stasiun 9 dan terendah $22,5^{\circ} \mathrm{C}$ pada stasiun 2. Apabila mengacu pada baku mutu kualitas perairan Kep. Men. LHK No.51 Tahun 2004, seluruh parameter kualitas perairan meliputi DO, suhu dan salinitas di Perairan Kawasan Taman Nasional Karimunjawa tidak melebihi baku mutu. Namun, stasiun 7 memiliki hasil salinitas yang melebihi baku mutu.

\section{PEMBAHASAN}

Menurut Affan (2011), bahwa suhu memiliki peran dalam kehidupan dan perkembangan biota laut, dimana ketika mengalami peningkatan kadar maka dapat mempengaruhi metabolisme biota, seperti konsumsi oksigen serta meningkatnya konsentrasi karbon dioksida (CO2). Hasil pada skenario 1 tersebut memiliki kondisi suhu optimum berkisar $24,4-24,8{ }^{\circ} \mathrm{C}$ dan minimum sekitar $20,4-20,8^{\circ} \mathrm{C}$. Menurut Affan (2011), konsentrasi suhu optimum untuk kepentingan budidaya ikan adalah $27-30{ }^{\circ} \mathrm{C}$ dan budidaya rumput laut $20-30{ }^{\circ} \mathrm{C}$. Mengingat daerah domain penelitian terdapat aktivitas budidaya rumput laut dan budidaya ikan, serta ekosistem mangrove dan lamun. Sehingga kondisi suhu tersebut dapat mendukung aktivitas pesisir dalam meningkatkan produktifitas primer perairan. Konsentrasi salinitas di Perairan Kawasan Taman Nasional Karimunjawa tidak terlalu berbeda jauh antar stasiun pengamatan $(32-34 \%)$ dan dapat dikatakan bahwa nilai yang didapatkan bersifat heterogen dengan variasi nilai yang tidak terlalu besar. Pada dasarnya perbedaan salinitas perairan akan terjadi karena adanya perbedaan penguapan dan presipitasi. Nilai salinitas tersebut tidak berbeda jauh dengan nilai salinitas perairan Utara jawa, dimana secara umum permukaan perairan utara jawa rata - rata berkisar antara 31 - 34\% (Meirinawati dan Riza, 2019). Konsentrasi salinitas dalam air laut akan mempengaruhi jasad jasad hidup akuatik berdasarkan kemampuan pengendalian berat jenis dan keragaman tekanan osmotik. Berdasarkan baku mutu air laut dalam Keputusan Menteri Negara Lingkungan Hidup No. 51 tahun 2004, sebagian besar nilai salinitas pada stasiun pengamatan masih sesuai dengan baku mutu air laut untuk biota laut.

Nilai pH yang baik berdasarkan baku mutu Kepmenneg LH No. 51 tahun 2004 untuk kawasan budidaya perikanan (biota laut) adalah $7-8.5$ dengan perubahan $<0.2$. Berdasarkan rata-rata tersebut dapat dikatakan $\mathrm{pH}$ perairan Kawasan Taman Nasional Karimunjawa masih dalam kisaran baku mutu dan masih bagus untuk kawasan budidaya perikanan dan kehidupan biota laut terutama karang, lamun dan ekosistem di dalamnya.

Menurut Kadim et al. (2017), kandungan oksigen dalam air yang ideal adalah antara $3-7 \mathrm{mg} / \mathrm{L}$. Konsentrasi DO yang lebih tinggi pada daerah Lagun Tengah dan Lagun Ujung kemungkinan disebabkan karena pada kedua perairan tersebut terdapat biota vegetasi laut (lamun) yang cukup banyak. Hal ini sesuai dengan pernyataan Salmin (2005) bahwa sumber utama oksigen (O2) dalam suatu perairan selain difusi dari atmosfer, yaitu berasal hasil fotosintesis organisme yang hidup dalam perairan tersebut. Kandungan DO pada suatu 
perairan sangat berhubungan dengan tingkat pencemaran, jenis limbah dan banyaknya bahan organik di suatu perairan. Oleh karena itu, berdasarkan konsentrasi DO yang diperoleh, maka dapat disimpulkan bahwa dari nilai DO perairan Kawasan Taman Nasional Karimunjawa tergolong dalam kategori tingkat pencemaran rendah dengan nilai $\mathrm{DO}>5 \mathrm{mg} / \mathrm{L}$.

\section{KESIMPULAN}

Berdasarkan penelitian yang telah dilakukan, didapatkan bahwa kualitas perairan meliputi konsentrasi suhu sekitar 29 - $30{ }^{\circ} \mathrm{C}$, salinitas 32 - 35 ppm, DO 9 - $11 \mathrm{mg} / \mathrm{L}, \mathrm{pH}$ 7,6 - 7,95 dan kecerahan 1 - 7 meter yang berdasarkan baku mutu perairan laut untuk kehidupan biota dari KEP. MEN. KLH RI No. 5 tahun 2004, perairan Kawasan Taman Nasional Karimunjawa sangat baik yang belum melebihi batas baku mutu. Perairan Kawasan Taman Nasional Karimunjawa sebagai wilsayah konservasi sangat memerlukan stasiun pemantauan karakteristik fisika-kimia perairan secara kontinu untuk memelihara kualitas lingkungan yang ada. Data dalam penelitian ini dapat dijadikan sebagai baseline bagi pemantauan kualitas air di perairan Kawasan Taman Nasional pada masa yang akan datang.

\section{DAFTAR PUSTAKA}

Handiani, D.N. 2004. Studi Sirkulasi Arus dan Transpor Polutan Cobalt dan COD (Chemical Oxygen Demand) di Perairan Pantai Cilegon untuk Memonitor Buangan Limbah Industri. [Tesis]. Magister Program Magister Teknik Lingkungan. ITB. Bandung.

Keputusan Menteri Lingkungan Hidup No. 51 .2004. Baku Mutu Air Untuk Biota. Menteri Lingkungan Hidup. Jakarta.

Kusumawati, I. 2016. Pemodelan Dinamika Arus Perairan Indonesia yang disebabkan Oleh Angin. Jurnal Perikanan Tropis, 3(1): 1-10.

Salmin. 2005. Oksigen Terlarut (DO) dan Kebutuhan Oksigen Biologi (BOD) Sebagai Salah Satu Indikator untuk Menentukan Kualitas Perairan. Oseana, 30(3): 21 - 26.

Suryanti, 2010. Degradasi Pantai Berbasis Ekosistem Di Pulau Karimunjawa Kabupaten Jepara. [Disertasi]. Sekolah Pascasarjana, Universitas Diponegoro, Semarang, $38 \mathrm{hlm}$.

Tanjung, R.H. Rechnelty, Baigo Hamuna dan Alianto. 2019. Assessment of Water Quality and Pollution Index in Coastal Waters of Mimika, Indonesia. Journal of Ecological Engineering. 20:87-84.

Tubalawony, S., E. Kusmanto, dan Muhadjirin. 2012. Suhu dan Salinitas Permukaan Sebagai Indikator Upwelling. LIPI, Jakarta.

Yusidarta, Isai, Sutris Haryanta, Yusuf Syaifuddin, N.D. Armojo, Mulyadi dan Agung Setiyadi. 2019. Mangrove-Tambak - $\quad$ Taman Nasional Karimunjawa. mari.blogspot.com/2018/06/gambar-peta-aerial-perambahan-mangrove.html

Wahyudin, Yudi, Dadan Mulyana, Agus Ramli, Novit Rikardi, Donny Suhartono dan A. T. Kesewo. 2019. Nilai Ekonomi Keanekaragaman Hayati Pesisir dan Laut Indonesia (The Economic Value of Coastal and Marine Biodiversity in Indonesia). Jurnal Pendidikan Insan Kamil Al Ihya, 2(2). 